\title{
What do Undergraduate Engineering Students and Preservice Teachers Learn by Collaborating and Teaching Engineering and Coding through Robotics?
}

\section{Dr. Jennifer Jill Kidd, Old Dominion University}

Dr. Jennifer Kidd is a Senior Lecturer in the Department of Teaching and Learning at Old Dominion University. Her research interests include engineering education, computational thinking, student-authored digital content, classroom assessment, especially peer review, and diversity issues. She currently has support from the National Science Foundation for two projects related to engineering education for preservice teachers.

\section{Dr. Krishnanand Kaipa, Old Dominion University}

Dr. Krishnanand Kaipa is an Assistant Professor and director of the Collaborative Robotics and Adaptive Machines (CRAM) Laboratory in the Department of Mechanical and Aerospace Engineering at the Old Dominion University. Dr. Kaipa received his BE (Hons.) in Electrical Engineering from Birla Institute of Technology and Science, Pilani, India in 1998, and his MS in 2004 and PhD in 2008, both in Aerospace Engineering from Indian Institute of Science, Bangalore. He worked as a postdoctoral associate at Department of Computer Science, University of Vermont and later at Department of Mechanical Engineering, University of Maryland, where he was also a research assistant professor. Dr. Kaipa's research interests include biologically inspired robotics, human-robot collaboration, embodied cognition, and swarm intelligence. Dr. Kaipa is a member of ASME and IEEE.

\section{Mr. Samuel J Sacks, Norfolk Public Schools}

After graduating from Virginia Tech with a BS in Sociology and Political Science in 2014, Mr. Sacks continued his education through Old Dominion University's K-6 teacher education masters program. Mr. Sacks is currently teaching 4th grade social studies at the Academy for Discovery at Lakewood in Norfolk, Virginia. He lives with his girlfriend, Hillary, and their cat, Snuggles.

\section{Dr. Stacie I Ringleb, Old Dominion University}

Stacie Ringleb is an associate professor in the Department of Mechanical and Aerospace Engineering at Old Dominion University. Dr. Ringleb received a B.S. in biomedical engineering from Case Western Reserve University in 1997, a M.S.E. from Temple University in Mechanical Engineering in 1999, and a PhD from Drexel University in Mechanical Engineering in 2003. She completed a post-doctoral fellowship in the Orthopedic Biomechanics Lab at the Mayo Clinic. Dr. Ringleb research interests include, biomechanics and rehabilitation engineering as well as multi-disciplinary approaches to improving engineering education.

\section{Dr. Pilar Pazos, Old Dominion University}

Pilar Pazos is an Associate Professor in the Department of Engineering Management and Systems Engineering at Old Dominion University, Norfolk, VA, USA. Her main areas of research interest are collaborative work-structures, virtual teams and team decision-making and performance.

\section{Dr. Kristie Gutierrez, Old Dominion University}

Dr. Gutierrez received her B.S. in Biology from the University of North Carolina at Chapel Hill in 2001, M.Ed. in Secondary Science Education in 2005 from the University of North Carolina at Wilmington, and Ph.D. in Science Education in 2016 from North Carolina State University. Dr. Gutierrez is currently serving as an Assistant Professor of Science Education in the Department of Teaching and Learning at Old Dominion University. She teaches elementary science methods and secondary science and mathematics methods courses with emphasis on multicultural education and equity pedagogies. Her research interests include both formal and informal STEM education, with specialization in the integration of engineering and computer science into science education through preservice and inservice educator development. 


\section{Dr. Orlando M Ayala, Old Dominion University}

Dr. Ayala received his BS in Mechanical Engineering with honors (Cum Laude) from Universidad de Oriente (Venezuela) in 1995, MS in Mechanical Engineering in 2001 and Ph.D. in Mechanical Engineering in 2005, both from University of Delaware (USA). Dr. Ayala is currently serving as Assistant Professor of Mechanical Engineering Technology Department, Frank Batten College of Engineering and Technology, Old Dominion University, Norfolk, VA.

Prior to joining ODU in 2013, Dr. Ayala spent three years as a Postdoctoral Researcher at the University of Delaware where he expanded his knowledge on simulation of multiphase flows while acquiring skills in high-performance parallel computing and scientific computation. Before that, Dr. Ayala held a faculty position at Universidad de Oriente at Mechanical Engineering Department where he taught and developed graduate and undergraduate courses for a number of subjects such as Fluid Mechanics, Heat Transfer, Thermodynamics, Multiphase Flows, Fluid Mechanics and Hydraulic Machinery, as well as Mechanical Engineering Laboratory courses.

In addition, Dr. Ayala has had the opportunity to work for a number of engineering consulting companies, which have given him an important perspective and exposure to the industry. He has been directly involved in at least 20 different engineering projects related to a wide range of industries from the petroleum and natural gas industry to brewing and newspaper industries. Dr. Ayala has provided service to professional organizations such as ASME. Since 2008 he has been a member of the Committee of Spanish Translation of ASME Codes and the ASME Subcommittee on Piping and Pipelines in Spanish. Under both memberships, the following Codes have been translated: ASME B31.3, ASME B31.8S, ASME B31Q and ASME BPV Sections I.

While maintaining his industrial work active, his research activities have also been very active; Dr. Ayala has published 90 journal and peer-reviewed conference papers. His work has been presented in several international forums in Austria, the USA, Venezuela, Japan, France, Mexico, and Argentina. Dr. Ayala has an average citation per year of all his published work of 44.78 .

\section{Dr. Lilian Maria de Souza Almeida, Old Dominion University}

Dr. Lilian Almeida received her Ph.D. in Engineering Education in 2019 and has been working with research in the field since 2016. 


\title{
What do Undergraduate Engineering Students and Preservice Teachers Learn by Collaborating and Teaching Engineering and Coding through Robotics?
}

\begin{abstract}
This research paper presents preliminary results of an NSF-supported interdisciplinary collaboration between undergraduate engineering students and preservice teachers. The fields of engineering and elementary education share similar challenges when it comes to preparing undergraduate students for the new demands they will encounter in their profession. Engineering students need interprofessional skills that will help them value and negotiate the contributions of various disciplines while working on problems that require a multidisciplinary approach. Increasingly, the solutions to today's complex problems must integrate knowledge and practices from multiple disciplines and engineers must be able to recognize when expertise from outside their field can enhance their perspective and ability to develop innovative solutions. However, research suggests that it is challenging even for professional engineers to understand the roles, responsibilities, and integration of various disciplines, and engineering curricula have traditionally left little room for development of non-technical skills such as effective communication with a range of audiences and an ability to collaborate in multidisciplinary teams. Meanwhile, preservice teachers need new technical knowledge and skills that go beyond traditional core content knowledge, as they are now expected to embed engineering into science and coding concepts into traditional subject areas. There are nationwide calls to integrate engineering and coding into PreK-6 education as part of a larger campaign to attract more students to STEM disciplines and to increase exposure for girls and minority students who remain significantly underrepresented in engineering and computer science. Accordingly, schools need teachers who have not only the knowledge and skills to integrate these topics into mainstream subjects, but also the intention to do so. However, research suggests that preservice teachers do not feel academically prepared and confident enough to teach engineering-related topics.

This interdisciplinary project provided engineering students with an opportunity to develop interprofessional skills as well as to reinforce their technical knowledge, while preservice teachers had the opportunity to be exposed to engineering content, more specifically coding, and develop competence for their future teaching careers. Undergraduate engineering students enrolled in a computational methods course and preservice teachers enrolled in an educational technology course partnered to plan and deliver robotics lessons to fifth and sixth graders. This paper reports on the effects of this collaboration on twenty engineering students and eight preservice teachers. T-tests were used to compare participants' pre-/post- scores on a coding quiz. A post-lesson written reflection asked the undergraduate students to describe their robotics lessons and what they learned from interacting with their cross disciplinary peers and the fifth/sixth graders. Content analysis was used to identify emergent themes. Engineering students' perceptions were generally positive, recounting enjoyment interacting with elementary students and gaining communication skills from collaborating with non-technical partners. Preservice teachers demonstrated gains in their technical knowledge as measured by the coding quiz, but reported lacking the confidence to teach coding and robotics independently of their partner engineering students. Both groups reported gaining new perspectives from working in
\end{abstract}


interdisciplinary teams and seeing benefits for the fifth and sixth grade participants, including exposing girls and students of color to engineering and computing.

\section{Introduction}

In addition to amassing expertise in their field, engineering students must learn to collaborate across disciplinary lines if they are to successfully negotiate today's complex challenges [1]. Increasingly, engineering solutions must integrate knowledge and practices from multiple disciplines and engineers must be able to recognize when expertise from outside their field can enhance their perspective and ability to develop innovative solutions. Tomek [2] discussed the importance of multidisciplinary teams in the engineering field and indicated that it is challenging even for professional engineers to understand the roles, responsibilities, and integration of various disciplines while working on problems that require a multidisciplinary approach.

Traditionally, engineering curricula have left little room for development of non-technical skills such as effective communication with a range of audiences and an ability to collaborate in multidisciplinary teams. This indicates an apparent gap between what is taught in academia and industry's expectations regarding engineers' skills [3]. Engineering practitioners have suggested that educators should raise engineering students' awareness of strategies for working with multidisciplinary peers [4]. Student outcomes delineated by the Accreditation Board for Engineering and Technology (ABET) reflect this emphasis. Outcome 3, "an ability to communicate effectively with a range of audiences," and outcome 5, "an ability to function effectively on a team whose members together provide leadership, create a collaborative and inclusive environment, establish goals, plan tasks, and meet objectives," [5] are intrinsically associated with the idea of multidisciplinary collaboration. Some engineering educators have begun to incorporate interdisciplinary learning experiences into their courses [6], but there is space for innovative approaches, and more research is needed to understand how to effectively accomplish this.

While engineering students need opportunities to practice collaborating with students outside their discipline, education students need experience with engineering, and particularly with coding and computational thinking. There are nationwide calls to integrate engineering and coding into PreK-6 education as part of a larger campaign to attract more students to STEM disciplines [7], [8]. The role of STEM in P-12 education has shifted from delivering STEM content knowledge to preparing students to be interested in, and committed to, pursuing careers in the STEM workforce [9]. In this context, schools need teachers who have not only the knowledge and skills to integrate these topics into mainstream subjects, but also the motivation to do so, and the desire to enthusiastically promote STEM occupations.

Despite moves to integrate computing into P-6 curriculum, most P-6 preservice teachers are not exposed to computing or computer science during professional preparation, and are unprepared to teach these topics [10]. Further, P-6 preservice teachers may not know that there is a connection between computing and engineering. If states are determined to institute computational thinking and engineering standards, teachers need to be prepared and equipped to do so [11]. 
This study researched an NSF-funded model for partnering undergraduate engineering students and preservice teachers to teach robotics activities to elementary students. The partnership was designed to tackle two disciplinary challenges, building interdisciplinary expertise for engineers and enhancing computing competence for P-6 educators, while addressing a broader interdisciplinary mission: attracting females and minorities into STEM fields. Undergraduate engineering students in a computational methods course were partnered with preservice teachers in an educational technology course at the same university. The students worked side-by-side on robotics activities to develop skill and confidence with basic programming concepts and block coding. After initial training activities, the engineering and education students led a diverse group of fifth and sixth grade students from a local school in similar robotics activities.

The design of the intervention draws from both constructionism [12] and social constructivism [13], [14]. Seymour Papert, the well known creator of the LOGO programming language, [12] believed that computational thinking should be taught using a constructionist approach, where students build programming expertise through creation of artifacts. Growing evidence demonstrating that robotics improves elementary students' STEM learning [15], and computational thinking development specifically [16], supports this theory. The researchers of this study share Papert's beliefs and hypothesized that the engineering students and preservice teachers would benefit from a hands-on approach. A second theory of learning, social constructivism, informs the interdisciplinary nature of intervention. It suggests that cross-disciplinary collaboration prompts students to experience new and different perspectives as they build knowledge together [13]. When engineering and education students develop lesson plans collaboratively, they share expertise from their respective disciplines with each other. They also bring personal experiences as students of a particular gender and background, with particular interests. These perspectives inform their decision making as they collaboratively design lessons to engage their fifth/sixth grade partners. This practice integrating multiple perspectives is essential for engineers tackling complex interdisciplinary problems and future teachers addressing the needs of an increasingly diverse student population.

This study aims to answer the following research questions:

1. How did collaborating to learn and lead robotics activities impact undergraduate engineering students' and preservice teachers' coding knowledge?

2. What roles did undergraduate engineering students and preservice teachers play while collaborating in a multidisciplinary challenge?

3. What did undergraduate engineering students and preservice teachers report learning from, and with, each other as they collaborated?

\section{Methods}

\section{Participants \& Context}

Twenty undergraduate engineering students in a computational methods course and eight preservice teachers (undergraduate students studying to become teachers) enrolled in an educational technology course partnered to plan and deliver robotics lessons to fifth and sixth graders. The meeting times for the two courses overlapped for 75 minutes a week enabling the 


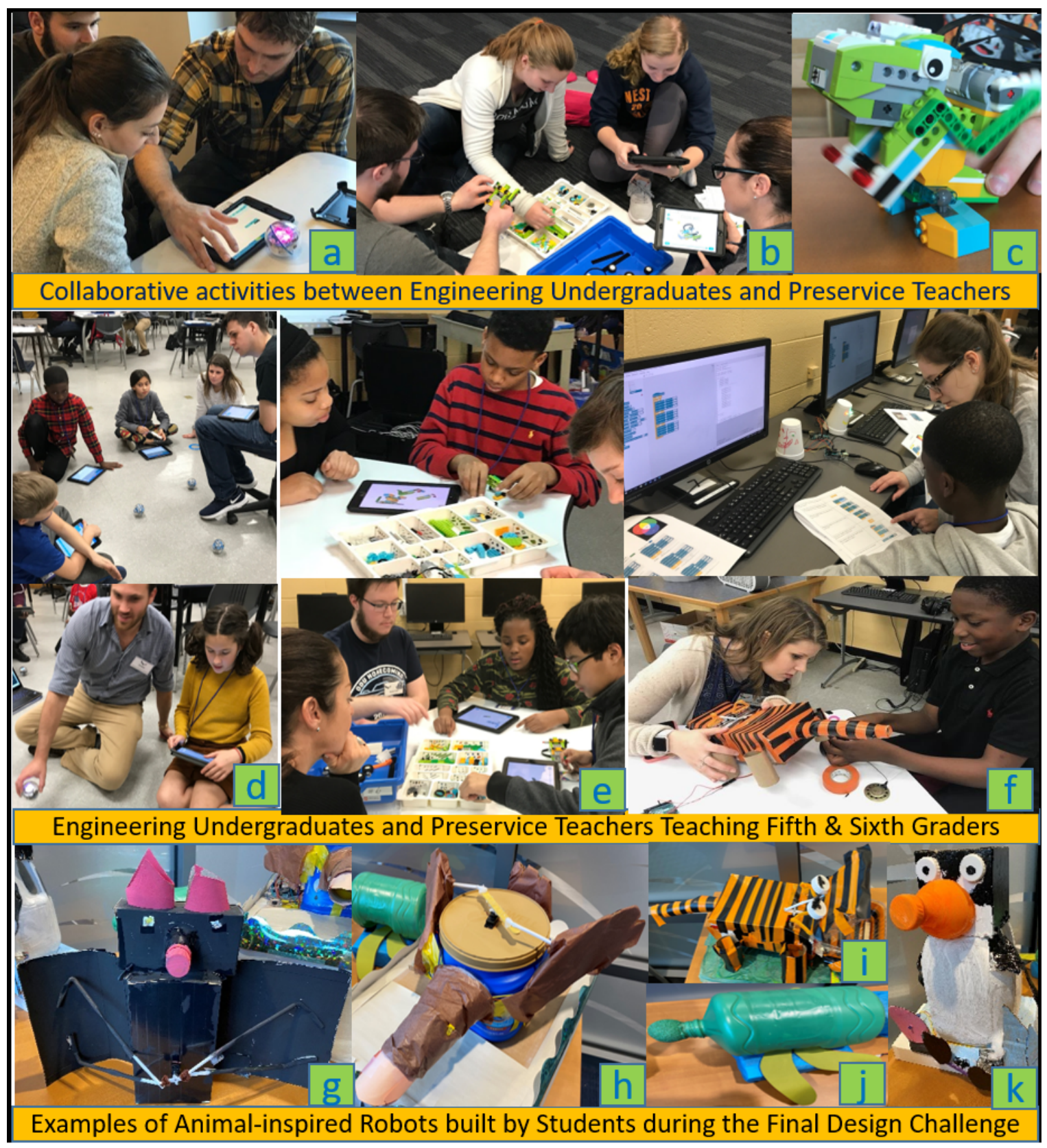

Figure 1: (a-b) Collaborative sessions between undergraduate students and preservice teachers held at the campus with Sphero robots (a) and LEGO WeDo Kits (b). (c) Example of an animal-inspired robot built by students using LEGO WeDo kit. (d-f) Collaborative sessions between fifth/sixth graders, preservice teachers, and engineering students at an after-school technology club using spheros (d), LEGO WeDo kits (e), and coding/robot building activities (f). ( $g$ - $k$ ) Examples of animal-inspired robots built by students: Bat (g), Duck (h), Tiger (i), Turtle (j), and Penguin (k).

engineering and education students to work collaboratively during several class sessions. Each preservice teacher was partnered with two or three engineering students. The teams engaged in five collaborative activities over the course of the semester. The first two collaborative sessions were held on the university campus, while the final three collaborative sessions took place at a 
local school during an after-school technology club for fifth and sixth graders (Figure 1). The education course instructor and education students led the technology club and were present for all club meetings. The engineering course instructor and engineering students were present for the club meetings that focused on robotics.

The interactions between the engineering and education team members were designed to be mutually beneficial, with dynamic roles that alternated between mentor, mentee, and co-learner, depending on the activity and expertise of the individual team members. In the first activity, engineering students taught preservice teachers about Sphero robots and how to use loops in block programming. In the second activity, preservice teachers and engineering students used LEGO WeDo kits to build and code an animal-inspired robot. Neither group had used these resources beforehand so the intention was for them to learn collaboratively. Following these two training activities, the teams brainstormed strategies for engaging fifth and sixth graders in similar activities and fleshed out the details on a 5Es lesson plan [17] developed by the education course instructor.

Three collaborative activities occurred during the after-school club and involved fifth/sixth graders alongside the college students. The first two activities mirrored the education/engineering student collaborative training sessions using Sphero and LEGO WeDo with one engineering student from each team supporting one education and two fifth/sixth graders. The college students helped the younger students program the Spheros to make a square and to navigate obstacles, and to assemble and code a LEGO animal robot. The third collaborative activity occurred during a robotics project. The robotics projects partnered one preservice teacher with approximately two fifth and sixth grade students to design, build, and program an animal-inspired robot using household (e.g. cardboard boxes, straws) and technical components (Arduino, servo motor, speaker, LEDs). Simple block coding via mBlock was used to add mobility, sound, and light to the robotic animals. During the final collaborative session, an engineering student from each team provided guidance on the robot's design. In particular, the engineering students' assistance was sought when building and coding a mechanism to add movement to the robot.

This study, while intended to directly impact the coding knowledge and interprofessional skills of education and engineering students, is also part of a larger movement to broaden participation in STEM fields, particularly engineering. The interventions were designed with this wider goal in mind. All of the preservice teachers were female, as were half of the participating fifth/sixth graders. Half of the preservice teachers were from minorities groups underrepresented in STEM, as were half of the fifth/sixth graders. To increase the appeal of engineering to these populations, weekly themes were adopted within the after-school technology club that framed the club's activities. These included engineering in music, sports, theme parks, toys and games, and film, with the overarching theme of engineering entertainment. The fifth and sixth graders partnered with the preservice teachers each week to deliver short presentations highlighting engineering contributions within each theme. In addition, the teams were encouraged to select their animal inspiration based on the fifth/sixth graders' interests and to decorate their robots and integrate musical programming. For example, one team used black and orange electrical tape to create the 
stripes on their robotic tiger and programmed it to roar. Awards were presented to teams at the end of the semester that recognized students' creative accomplishments in their robot designs.

\section{Measures}

A mixed-methods research approach was applied in this study [18]. A coding quiz was developed by the researchers to assess computational thinking concepts (sequencing, looping, variables, conditionals, and debugging) aligned with Virginia's fifth grade Computer Science standards. Fourteen code-agnostic multiple-choice items and one short-answer question were adapted from two established instruments [19], [20]. These items were intended to measure whether or not the preservice teachers understood the coding and computational concepts they would be expected to teach in a fifth grade classroom. Since these concepts were the focus of the coding activities that occurred during the collaborative sessions, the researchers were interested in knowing whether or not the coding knowledge of the education and engineering students in these areas was enhanced over the semester.

Written student reflections were collected to add a qualitative perspective to the study. Both engineering and education students submitted 1-2 page reflections after completing each robotics activity with the fifth and sixth graders. Open-ended prompts directed students to describe what they were teaching, the roles they played during the lesson, what they felt most/least confident about, their impressions of the success of their lessons, and what they learned from the experience.

Inferential statistical tests were used to make within-group and between-group comparisons on the coding quiz as t-tests are ideal for small sample sizes. Qualitative content analysis [21] was used to identify emergent themes related to coding knowledge, team roles, and student learning. Two researchers identified and agreed on a set of codes after analyzing a small sample of students' written reflections. The codes were compared and reviewed until 100\% consensus was reached. A selection of themes were then generated for the purpose of reporting the analysis.

\section{Results}

RQ1: How did collaborating to learn and lead robotics activities impact undergraduate engineering students' and preservice teachers' coding knowledge?

Engineering students performed well across all coding concepts and scored significantly better than preservice teachers $(F=9.983, p=0.004)$, however there was no significant difference between engineering students' pre-test and post-test scores (pre-test $\mathrm{M}=10.47, \mathrm{SD}=2.83$; post-test $\mathrm{M}=10.79, \mathrm{SD}=2.82)$. The preservice teachers' mean score increased from $5.75(\mathrm{SD}=$ $2.31)$ to $6.88(\mathrm{SD}=3.23)$, which marked a significant difference $(\mathrm{t}=-2.553, \mathrm{p}=0.038)$.

Preservice teachers performed best on items assessing sequencing and loops. They struggled on questions incorporating spatial reasoning, and items assessing conditionals, especially when calculations or comparators were included. Preservice teachers showed the most improvement coding a robot to turn at right angles and using a loop to form a square, activities that were explicitly covered in the Sphero lesson. Two questions requiring students to envision a coordinate system and engage in algebraic thinking to determine a sprite's movement were missed by almost all participants, education and engineering students alike (see Figure 2). 
RQ2: What roles did undergraduate engineering students and preservice teachers play while collaborating in a multidisciplinary challenge?

Engineering students' reflection comments were generally positive, recounting enjoyment interacting with elementary students. When asked about their roles during the lessons at the after-school club, the engineering students described supporting the preservice teachers. For example, one engineering student said:

My partner was teaching the students while I was supporting the lessons they were teaching. I was satisfied with this because I am more comfortable supporting than teaching.

Many engineering students appeared to see their role as a content expert, focusing on what was being taught rather than how it was taught. One engineering student explained:

We decided beforehand that I would go over the more technical and math side of things and that [my partner] would go over the 'how-to' portion of the lesson. This was due to her being more adept teaching the children and me being more familiar with the material.

A few engineering students described taking the lead explaining engineering concepts, for example, "any point that required an engineering explanation, I took over" and "my role in teaching the lesson was to ask and answer engineering related questions and to engage the students in engineering thought processes." They reported feeling most confident in their ability to build and code, and less confident in their ability to engage the children. While the interdisciplinary collaboration may have been a new challenge for many of the engineering students, the qualitative data suggests that many of them may have tried to carve out a role that allowed them to remain within their comfort zones.

The preservice teachers expressed both positive (e.g. confidence, success, enjoyment) and negative sentiments (e.g. lack of confidence, feeling unprepared, feeling unsuccessful) in their reflections. Some preservice teachers discussed leading coding activities. For example, one preservice teacher said, "I felt really confident in delivering the lesson and my ability to explain the concepts of looping and angles." However, more preservice teachers reported feeling confident interacting with the children, but deferring to engineering partners to explain coding concepts and answer coding-related questions. One preservice teacher said:

He taught the majority of the lesson because we felt he was better at explaining the concepts. I interjected as necessary. There were parts of the lesson not made simple enough for the kids to understand so that is where I came in.

Almost all of the preservice teachers described learning from their engineering partners and finding this peer learning beneficial. For example, one participant said, "He taught me concepts about coding that I didn't know before and when I didn't understand them still he would explain them in a different way." One preservice teacher portrayed a reciprocal learning experience, "he tried his best to teach me how to code and work sphero and I gave him tips of how to engage with the children." Another preservice teacher characterized a one-way learning experience: 
I definitely learned a lot from my engineering students. However, I feel like they were not as receptive to learning from me.

As with the engineering students, many preservice teachers seemed to try to find a role within their comfort zones. However, the preservice teachers were required to lead several technology club sessions without their engineering partners, including ones that focused on robotics, and were therefore more likely to be forced into new, and potentially uncomfortable roles. It is not surprising then, that the preservice teachers' reflections were more likely than the engineering students' to include negative sentiment. For example, one preservice teacher noted, "at no point did I feel confident."

\section{RQ 3: What did undergraduate engineering students and preservice teachers report learning} from and with each other as they collaborated?

Many engineering students reported gaining communication and collaboration skills. One remarked: "I learned how to break down complicated problems and how to use simpler terms instead of engineering specific jargon." The engineering students were split in describing the impact on their coding knowledge - half reported enhanced understanding, while the other half reported little to no benefit. One engineering student said: "I felt like I understand the concepts more because I had to think of it in different ways in order to teach the student," while another said, "The material was very basic so what we were teaching is already an area I am confident in."

The qualitative data suggests preservice teachers learned about programming from their engineering partners and from interacting with the fifth and sixth graders. They reported learning by preparing to teach the children and from interacting with the children during the lessons. One preservice teacher said, "since I had to teach the kids about it, I had to learn the information for myself." Another participant explained:

As my student was learning, I was learning. We were putting in random pieces of coding and guessing on what they were going to do.

While the preservice teachers did learn from the experience, most indicated that they did not feel confident with coding, and felt unprepared to lead robotics activities. One of the participants explained: "It helped me get a bit more comfortable with the idea of it, but at the same time though, I wouldn't feel comfortable teaching it on my own." A few preservice teachers also acknowledged advantages from working in a multidisciplinary context, offering benefits such as the opportunity to learn more about job opportunities for their future students, and gaining new perspectives, especially about engineering.

\section{Discussion and Conclusions}

The fields of engineering and elementary education are both facing new challenges when it comes to preparing undergraduate students for their respective professions. Engineering students need interprofessional skills that go beyond technical and disciplinary expertise, and help them address problems requiring a multidisciplinary approach. Meanwhile, preservice teachers need technical knowledge and skills that go beyond traditional core content knowledge, as they are 
now expected to embed engineering into science and coding concepts into traditional subject areas.

This study researched an NSF-supported model for partnering engineering students and preservice teachers to tackle these two disciplinary challenges, while contributing to the wider interdisciplinary mission of broadening participation in STEM fields. The goals of the intervention were to provide an opportunity for engineering students to work on an interdisciplinary team and to improve preservice teachers' coding knowledge. The researchers hoped that the intervention would have positive benefits for the engineering students, reinforcing their coding knowledge, and enhancing their ability to interact with non-technical audiences. Simultaneously, they hoped that an increase in preservice teachers' skills and confidence would enhance the likelihood that they would teach coding and engineering in their future classrooms.

Engineering and education students collaborated in small teams over five sessions to learn and teach robotics. In the first two, the undergraduate students explored block programming through Sphero and WeDo robotics. In the last three, the college students led fifth and sixth graders in similar robotics activities. A coding quiz was developed by the authors from existing instruments to assess concepts included in the state's computer science standards for fifth graders. The preservice teachers showed a significant increase in coding knowledge after the intervention, while the coding knowledge of the engineering students did not change. Student reflections suggest the preservice teachers gained new coding expertise, but still lacked the confidence to lead robotics activities independently. Some engineering students reported the intervention enhanced their understanding of coding, while others reported little to no benefit.

There were clear distinctions in the roles the engineering and education students played during the collaborations, especially as they were leading activities with the fifth and sixth graders. The engineering students tended to see their role as content experts and often took the role of explaining engineering coding concepts. Meanwhile, the education students reported feeling most confident structuring the activities and engaging the children, and reported deferring to their engineering partners for technical expertise. While there were exceptions to these roles, there were marked tendencies for the undergraduates to fall into these comfort zones, and not to embrace roles outside of traditional expectations for their disciplines. The researchers suggest the collaboration activities may need to be deliberately structured to persuade students to embrace roles outside their comfort zones.

Preservice teachers reported learning from their engineering partners as well as from their experience of teaching fifth and sixth graders. Engineering students were more likely to report learning from the experience generally rather than directly from their education partners. If the goal is for engineering students to learn directly from the education students, they would need to value the knowledge the preservice teachers bring to the collaboration. To promote this mindset, the engineering students could have increased responsibility for the lesson planning and delivery, and the instructors could deliberately draw attention to the value of pedagogical knowledge. The engineering students did report gaining communication and collaboration skills, particularly from having to break down and explain concepts with simple terminology. Enhanced planning responsibility could expand these benefits while simultaneously increasing the value of the preservice teachers' expertise. Societal norms that value traditionally male-dominated fields, like 
engineering, over traditionally female-dominated fields, like teaching, may contribute to perceptions that the engineering students have valuable knowledge and skills to share, but education students do not. The researchers recognize the importance of stressing the value both groups of students bring to the collaboration. This practice may also help engineers recognize how expertise from outside their field can enhance their ability to develop innovative solutions.

These preliminary findings suggest that preservice teachers and engineering students can benefit from working together. This is an important new finding as there are few prior studies which examine the effects of partnering these two populations. Given the complementary new challenges facing faculty in these fields, this study is timely and offers a promising model for a mutually beneficial partnership between the disciplines. More needs to be learned, however, about how to structure the collaborations to maximize the benefit. Preservice teachers gained coding knowledge, but did not develop the confidence needed to operate independently of their engineering partners. Engineering students reported gaining communication skills, but this is difficult to quantify, and their coding knowledge did not improve, at least not on the concepts aligned with state standards. The researchers suggest planning activities that acknowledge the value of the skills and knowledge unique to each discipline and requiring students to teach and learn from each other. Students may also rate the effectiveness of their peers' lessons or presentations, which can also serve as a measure of communication skills.

As mentioned earlier in our preliminary findings, engineering students did not report considerable gains in coding knowledge and thereby seemed not to fully see the larger benefits of the collaboration. The researchers plan to address these issues in future interventions in the following ways. At the outset, when introducing engineering students to the intervention, instructors must emphasize the beneficial outcomes of participating in a cross-disciplinary intervention with practitioners outside traditional engineering fields. For example, when engineering students brainstorm with preservice teachers and elementary students, they are likely to hear approaches that differ considerably from what they or their fellow engineers might imagine. This idea diversity may enhance their creativity and lead them to develop more innovative solutions that appeal to a broader audience. The ability to empathize, compromise, and communicate effectively within professionally and demographically diverse groups prepares engineering students to address real-world problems that have greater societal impact, in addition to engaging in engineering problems of technical nature. The engineering students need to understand that their participation in the project may help them collaborate on diverse teams in the future, and thereby design better products that integrate more viewpoints. Until now, the education students took the lead role in developing lesson plans with help from their education instructor, while engineering students engaged mainly during the actual delivery of the planned lessons. In an ongoing extension of this work, researchers are exploring a modified model of role-division by having engineering students engage in developing lesson plans on par with their education partners. This greater engagement in lesson plan development is expected to enhance engineering students' ability to effectively present and communicate their technical ideas and designs to people outside their fields of expertise. 
This intervention can be improved in still other ways to increase benefits for engineering students. Apart from the collaborative project described in this study, the engineering students also work on a separate hands-on project toward the goals of the engineering course. However, until now, it was decoupled from the robot-building/coding project they do with their education and elementary student partners. The researchers are exploring a model that connects these two projects by having engineering students bootstrap from the brainstorming, coding, and robot building experiences gained when they collaborated with their education partners, and extend to a more in-depth technical project later in the semester, while adhering to similar project themes and ideas. This coupling of projects is expected to enhance the engineering students' perceived values of the project and also contribute to reinforcing their coding and engineering knowledge.

This study investigated a multidisciplinary collaboration between undergraduate engineering and education students to learn and teach robotics. It adds to existing research supporting robotics as a viable pedagogical approach for preservice teachers to learn coding concepts [22], and affirms Papert's constructivist ideology. Engineering and education students reported gaining new perspectives from working in interdisciplinary teams and both reported seeing benefits for the fifth and sixth grade participants, including exposing girls and students of color to engineering and computing. The research on this project is ongoing and will continue to add new insights to this intervention. 
12. The cat's current position is $(-20,5)$. When the flag is clicked, the cat will...
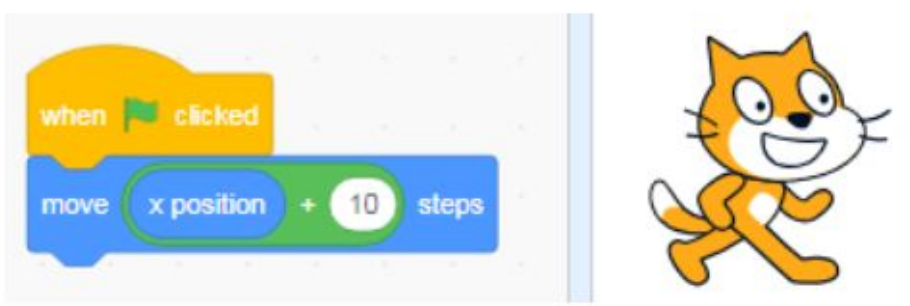

Move to its left

Move to its right

Move upwards

Not move at all

13. Where will the cat be after the flag is clicked a second time?

$(0,5)$

$(20,5)$

$(-30,5)$

$(-50,5)$

Figure 2. Items missed by the majority of engineering and education students 
3. Sandeep is using the same robot and commands. He wants his robot to move 5 steps to the left. The code did not work as expected. How can he fix his code?
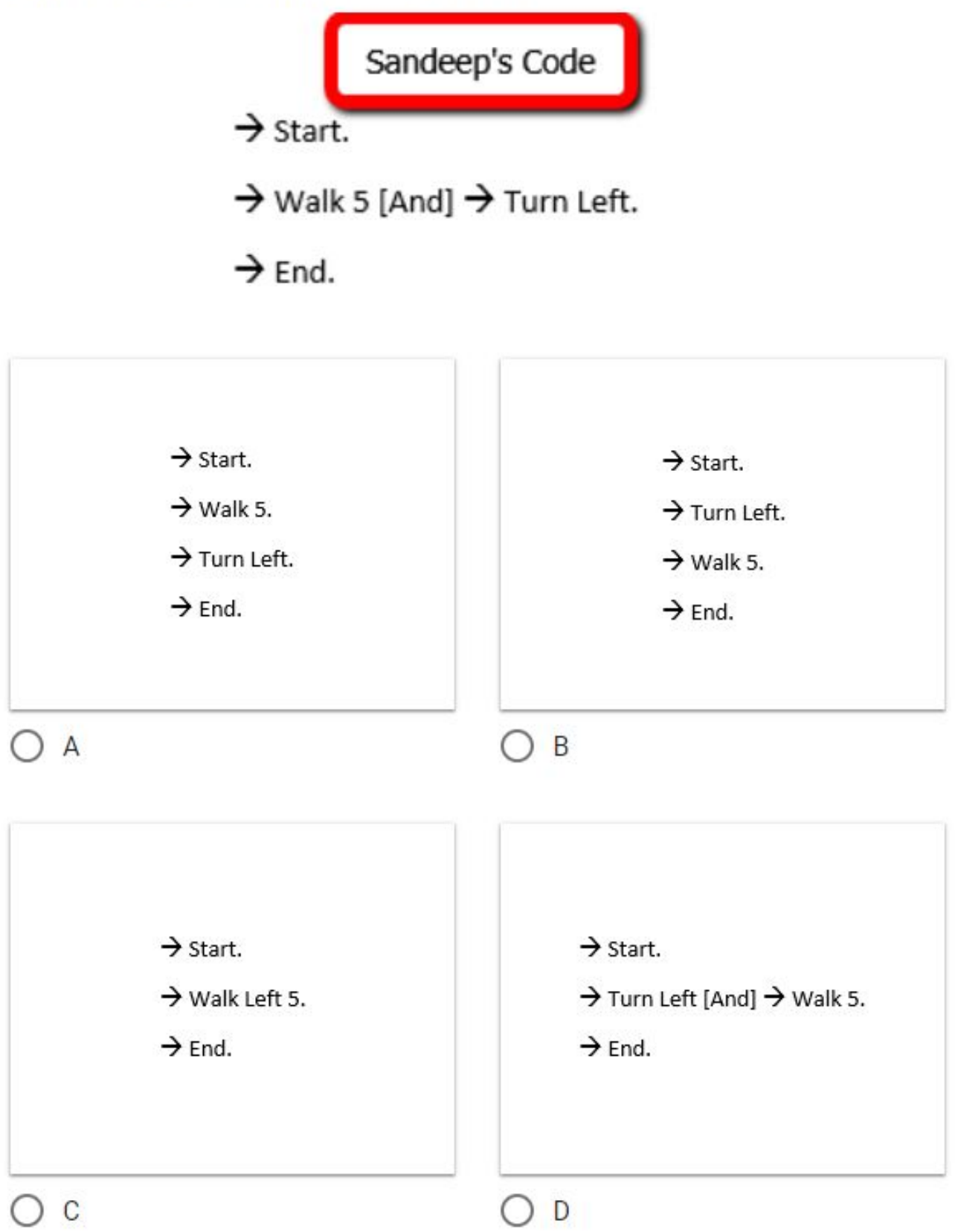

Figure 3. CS Quiz Item on which Preservice teachers improved (\#1) 


\section{Choose the most efficient option for creating a square}

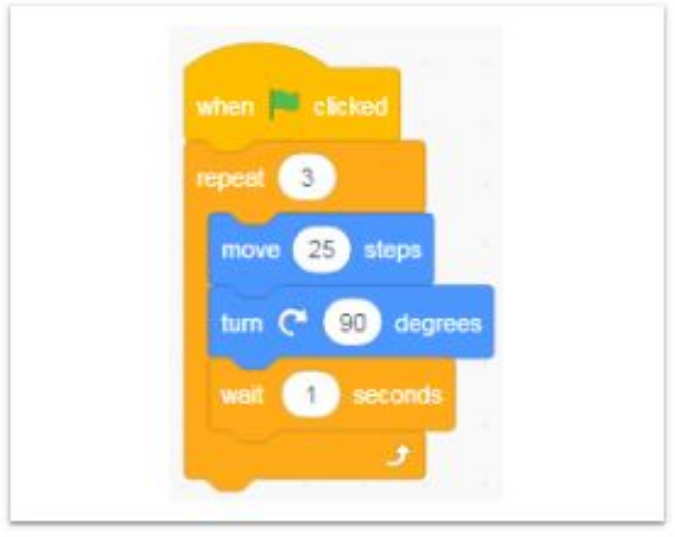

A

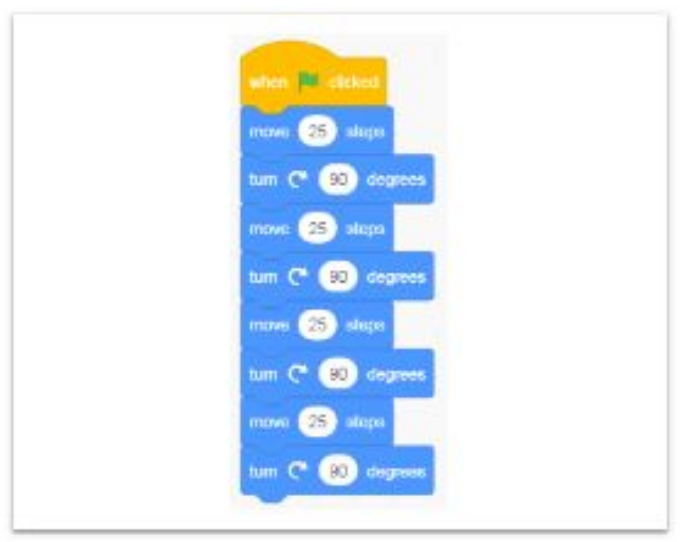

C

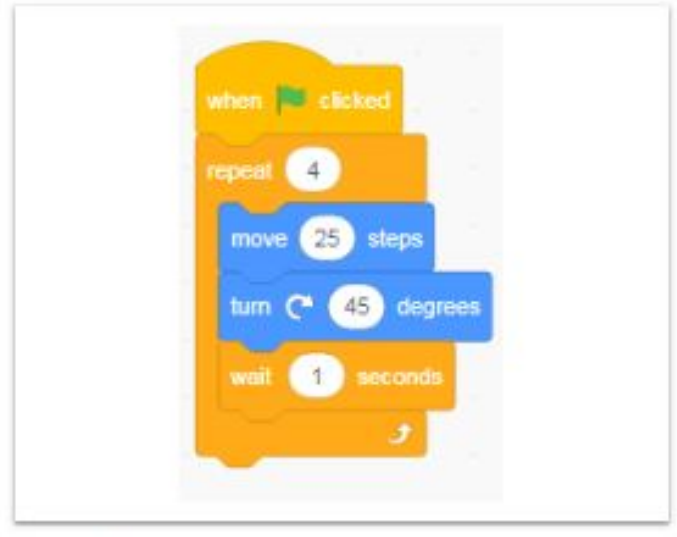

$\bigcirc \mathrm{B}$

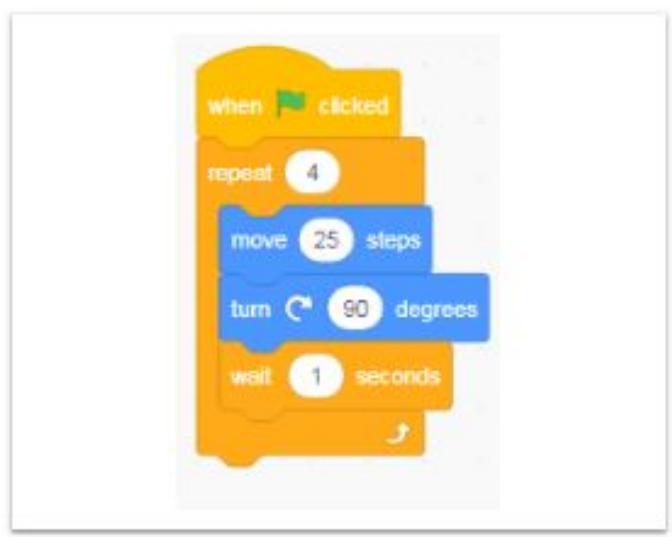

O D

Figure 4. CS Quiz Item on which Preservice teachers improved (\#2)

\section{References}

[1] D. M. Richter and M. C. Paretti, "Identifying barriers to and outcomes of interdisciplinarity in the engineering classroom," European Journal of Engineering Education, vol. 34, no.1, pp. 29-45, 2009.

[2] S. Tomek, "Developing a multicultural, cross-generational, and multidisciplinary team: An introduction for civil engineers," Leadership and Management in Engineering, vol. 11, no. 2, pp. 191-196, 2011.

[3] L. M. S. Almeida, K. Becker, and I. Villanueva, "Understanding Industry's Expectations of Engineering Communication Skills," in Proceedings of the American Society for Engineering Education Annual Conference, Tampa, FL, 2019.

[4] E. C. Wisniewski, "Novice engineers and project management communication in the workplace," Technical Communication, vol. 65, no. 2, pp. 153-168, 2018. 
[5] Accreditation Board for Engineering and Technology. Criteria for Accrediting Engineering Programs (2020). Retrieved from http: https://www.abet.org/wp-content/uploads/2018/11/E001-19-20-EAC-Criteria-11-24-18.pdf

[6] D. Richter, M. Paretti, L. McNair, and M. Borrego, "Assessing student perspectives of interdisciplinary collaboration," In Proceedings of the American Society for Engineering Education Annual Conference, 2009.

[7 ] National Research Council. 2012. A Framework for K-12 Science Education: Practices, Crosscutting Concepts, and Core Ideas. Washington, DC: The National Academies Press. https://doi.org/10.17226/13165.

[ 8] State of Computer Science Education, 2019, https://advocacy.code.org/2019 state of cs.pdf

[9] M. M. Mahmoud, K. H. Becker, M. L. Lunghurst, R. R. Dupont, N. Mesner, and J. Dorward, "Factors influencing the interest level of secondary students going into STEM fields and their parents' perceived interest in STEM (Evaluation)," in Proceedings of the American Society for Engineering Education Annual Conference, Salt Lake City, UT, 2018.

[10] M. Hsu, S. Purzer, and M. E. Cardella, "Elementary teachers' views about teaching design, engineering, and technology," Journal of Pre-College Engineering Education Research (J-PEER), vol. 1, no. 2, 5, 2011.

[11] S. Grover and R. Pea, "Computational thinking in K-12: A review of the state of the field," Educational Researcher, vol. 42, no. 1, pp. 38-43, 2013.

[12] S. Papert, Mindstorms: Children, Computers, and Powerful Ideas, New York, NY: Basic Books, Inc, 1980.

[13] J. Piaget, The Equilibration of Cognitive Structure: The Central Problem of Intellectual Development, Chicago: University of Chicago Press, 1985.

[14] L. S. Vygotsky, Mind in Society: The Development of Higher Psychological Processes, Harvard University Press, 1980.

[15] C. Rogers and M. Portsmore, "Bringing engineering to elementary school," Journal of STEM Education, vol. 5, nos. 3 and 4, pp. 17-28, 2004.

[16] M. U. Bers, L. Flannery, E. R. Kazakoff, and A. Sullivan, "Computational thinking and tinkering: Exploration of an early childhood robotics curriculum," Computers \& Education, vol. 72, pp. 145-157, 2014.

[17] R. W. Bybee, J. A. Taylor, A. Gardner, P. Van Scotter, J. C. Powell, A. Westbrook, and N. Landes, "The BSCS 5E instructional model: Origins and effectiveness," Colorado Springs, Co: BSCS, 5, pp. 88-98, 2006.

[18] J. W. Creswell and V. L. P. Clark, 2007, Designing and Conducting Mixed Methods Research: Wiley Online Library, 2007.

[19] J. Shen, Transformative Robotics Experience for Elementary Students, Items-FormA fall 2015, 2017.

[20] I. Zur Bargury, B. Pârv, and D. Lanzberg, "A nationwide exam as a tool for improving a new curriculum," in Proceedings of ITiCSE'13, pp. 267-272. Canterbury, England, UK, 2013.

[21] Y. Zhang and B. M. Wildemuth, "Qualitative analysis of content," Applications of Social Research Methods to Questions in Information and Library Science, 308, 319, 2009.

[22] K. Jaipal-Jameni, and C. Angeli, "Effect of robotics on elementary preservice teachers' self-efficacy, science learning, and computational thinking," Journal of Science Education and Technology, vol. 26, no. 2, pp. 175-192, 2017. 